\title{
Developing AIDS - The Dangerous Conjugation and Transformation of HIV : An In-depth Analysis
}

\author{
K. BULBUL SARWAR* \\ School of Science and Technology, Bangladesh Open University, Gazipur-1705, Bangladesh
}

\begin{abstract}
HIVIAIDS spreads so quickly and so destructively that it supersedes all disasters ever attacks human civilization. No branch of scientists can declare them aloof or abstain from it. So the agriculturists are very closely concern with its research-issues, nutritional remedies and agro-based care. We know, HIV stands for human immunodeficiency virus. It is the virus that causes AIDS. A member of a group of viruses called retroviruses, HIV infects human cells and uses the energy and nutrients provided by those cells to grow and reproduce. AIDS stands for acquired immunodeficiency syndrome. It is a disease in which the body's immune system breaks down and is unable to fight off infections, known as "opportunistic infections," and other illnesses that take advantage of a weakened immune system. Opportunistic infections are various in types and it needs not only the care from health professionals rather it deserves agriculturists, nutritionists and social scientists to combat together. When a person is infected with HIV, the virus enters the body and lives and multiplies primarily in the white blood cells. These are immune cells that normally protect us from disease. The hallmark of HIV infection is the progressive loss of a specific type of immune cell called T-helper, or CD4 cells. As the virus grows, it damages or kills these and other cells, weakening the immune system and leaving the person vulnerable to various opportunistic infections and other illnesses ranging from pneumonia to cancer. Understanding how the human immunodeficiency virus (HIV) works inside the human cell gives all scientists important ways about how to attack it at its most vulnerable points and clues to start research. Knowing the secrets of how the virus functions and reproduces itself -- a process called its 'lifecycle'- can help scientists design new drugs and nutritional supplements those are more effective at suppressing HIV and support the affected lives. This study will draw a clear and easy-to-understand picture for every scientist, obviously the agriculturists too, being alert and keeping their lives safe from this fatal conjugation of HIV and help to invent natural and/or plant remedies to prevent or suspend HIV's aggression, as long as we concern.
\end{abstract}

Key words: HIV, AIDS, retro virus, HIV viral transformation.

\section{SITUATION ANALYSIS}

Five people worldwide die of AIDS every minute of every day (Muna L. Romance and Pleasure: Understanding the Sexual Conduct of Young People in Dhaka in the Era of HIV and AIDS (2005), UPL, Dhaka, Bangladesh). In Asia and the Near East, 7.1 million people are HIV positive (CDC, Division of HIVIAIDS Prevention, Atlanta, USA). Four hundred and fifty-seven thousand people in the region die annually from HIVIAIDS-related illnesses, accounting for about one-sixth of deaths worldwide (World AIDS Data, Fact Sheet, 2006).

\footnotetext{
* Corresponding author: Assistant Professor, SST, BOU. Phone: 9291101-4, Ext. 238; E-mail: kbsarwar@gmail.com

(C) 2006 School of Agriculture and Rural Development, Bangladesh Open University, All rights reserved.
} 


\section{K. Bulbul Sarwar}

While the numbers of those infected may seem low compared to Africa, they have the potential to explode. The huge populations in Asia hide the fact that epidemics are expanding rapidly in Burma, China, India, Indonesia and Vietnam (Hoque ANE, Why AIDS is a big problem for Bangladesh? (2006). Together these countries have almost 80 percent of the HIV infections in Asia and the Near East. By 2010, Asia could lead the world with up to 40 million HIV-infected people (UNAIDS (2006), 'Population Mobility and AIDS', Technical Update, February).

At the end of 2001 UNAIDS and WHO estimated that 13,000 people were living with HIVIAIDS in Bangladesh (Alauddin M, Ex-Procurement Consultant, IDA/DFID funded HIVIAIDS Prevention Project, Bangladesh). As reported by the Bangladesh AIDS prevention and control project, up to December 2005, total reported number of people living with HIV is 465 , total reported cases developed AIDS is 73 and death is 30, and the number of new case in 2005 is 102 (ICDDR,B, AIDS Report-2006). While no demographic information was available for approx. $41 \%$ of HIV cases, $36 \%$ cases were immigrant workers mainly coming from Sylhet division. Of the HIV cases detected approx. $10 \%$ were housewives, $2 \%$ were commercial sex workers (CSWs) and $2 \%$ were HIV positive infants. HIV infections were 4\% in intravenous drugs user (IDUs) in 2004, but in 2005 it is $4.9 \%$. $70 \%$ of IDUs exchange syringe among the (ICDDR,B, AIDS Report, Internet UpdateMarch-2007).

On the World AIDS day 2006, Bangladesh government officially declared only 482 HIV positive cases (Special Correspondent, New Age, Dhaka, December 2, 2006). Being not only country of 148 million people within the pocket of $144,000 \mathrm{sq} . \mathrm{km}$. area, but its locked-jaw geographical position between India and Myanmar, both of which has high prevalence (50\%) of HIV, indicates that Bangladesh is passing 'window opportunity', and without HIV prevention program we will have epidemic of HIVIAIDS, which would be disastrous for this poor country (Hoque ANE, Why AIDS is a big problem for Bangladesh? - Internet).

\section{The Transmission}

1. How many people are affected by HIVIAIDS?

The Joint United Nations Program on HIVIAIDS (UNAIDS) estimates that there are now about 40 million people living with HIV or AIDS worldwide. Most of them do not know they carry HIV and may be spreading the virus to others.

Table 1. The latest statistics on the world epidemic of AIDS \& HIV, 2006

\begin{tabular}{lll}
\hline \multicolumn{1}{c}{ Area } & \multicolumn{1}{c}{ Estimate } & \multicolumn{1}{c}{ Range } \\
\hline \hline People living with HIVIAIDS in 2006 & 39.5 million & $34.1-47.1$ million \\
Adults living with HIVIAIDS in 2006 & 37.2 million & $32.1-44.5$ million \\
Women living with HIVIAIDS in 2006 & 17.7 million & $15.1-20.9$ million \\
Children living with HIVIAIDS in 2006 & 2.3 million & $1.7-3.5$ million \\
People newly infected with HIV in 2006 & 4.3 million & $3.6-6.6$ million \\
Adults newly infected with HIV in 2006 & 3.8 million & $3.2-5.7$ million \\
Children newly infected with HIV in 2006 & 0.53 million & $0.41-0.66$ million \\
AIDS deaths in 2006 & 2.9 million & $2.5-3.5$ million \\
Adult AIDS deaths in 2006 & 2.6 million & $2.2-3.0$ million \\
Child AIDS deaths in 2006 & 0.38 million & $0.29-0.50$ million \\
\hline
\end{tabular}

Adults in this report are defined as men and women aged 15-49. Children orphaned by AIDS are those children under 18 who have lost one or both parents to AIDS.((UNAIDS \& WHO - 2006); AVERT AIDS Education \& Research Trust (England) http://www.avert.org)

Since the beginning of the epidemic, AIDS has killed more than 30 million people worldwide. AIDS has replaced malaria and tuberculosis as the world's deadliest infectious disease among adults and is the fourth leading cause of death worldwide. More than 14 million children have been orphaned by the epidemic (The LifeBoat http://captainsport.com/thelifeboat/Connections.htm). 


\section{Route of Entry}

People who have HIV can give it to others when certain of their body fluids (blood, semen ["cum"], vaginal fluids, or breast milk [for infants only] pass into another person's body. There are three main ways that our body fluids can get into another person's body:

- by having unprotected sex (sex without a condom), that involves anal, vaginal or oral penetration;

- $\quad$ by sharing "works" (needles and syringes, cookers, cottons and water) when injecting drugs or other substances;

- $\quad$ from a mother to her child before birth, during birth, or while breast-feeding. (The chance of having a healthy baby can be greatly increased with proper medical care) (www.thebody.html).

\section{HIV is a Continuum}

Most of us are used to thinking of disease in very simple terms: if you feel sick, you are sick; if you feel healthy, you are healthy. However, because HIV may be causing subtle changes in the immune system long before an infected person feels sick, most doctors have adopted the term "HIV Disease" to cover the entire HIV spectrum, from initial infection to full-blown AIDS - which also be called "Advanced HIV Disease"(Gyarmathy VA et al, Evaluation of a comprehensive AIDS education curriculum in Hungary - the role of good educators. J Adolesc 2002; 25(5):495-508).

The continuum that follows and its stages are representative of the experience of many people with HIV. The time that it takes for each individual person to go through these stages is varied. For most people, however, the process of HIV disease is fairly slow, taking several years from infection to the development of severe immunodeficiency (Igarashi T, et al, Persistent infection with SIVmac chimeric virus having tat, rev, vpu, env and nef of HIV type 1 in Macaque monkeys. AIDS Research and Human Retroviruses 1994; 10:1021-9).

Viruses cannot reproduce without the aid of a living cell. Although HIV can infect a number of cells in the body, the main target is an immune cell called a lymphocyte, more specifically a CD4 helper cell, a type of T-cell. T-cells are an important part of the immune system because they help facilitate the body's response to many common but potentially fatal infections. Without enough Tcells, the body's immune system is unable to defend itself against many infections. By ways that are not yet completely understood, HIV's life cycle directly or indirectly causes a reduction in the number of T-cells in the body, eventually resulting in an increased risk of infections.

HIV enters the bloodstream and begins to take up residence in the cells. People with HIV are considered to be infectious immediately after infection with the virus. Although some studies suggest that the level of infectivity varies over time depending on the stage of the disease in which the person is, it is not possible for most HIV-infected people to find out what their level of infectivity is (Grassly NC, et al. The economic impact of HIVIAIDS on the education sector in Zambia. AIDS 2003; 17(7):1039-1044).

A person with HIV is infectious at all times. Also, a person does not need to have symptoms or look sick to have HIV. In fact, people may look perfectly healthy for many years despite the fact that they have HIV in their bodies. The only way to find out if a person is infected is by taking an HIV antibody test (Perez F, Dabis F. HIV prevention in Latin America: reaching youth in Colombia. AIDS Care - Psychological and Socio-Medical Aspects of AIDS/HIV 2003; 15(1):77-87).

After HIV enters the body - through unsafe sex, contaminated needles, blood transfusions or from mother to child (vertical or perinatal transmission) - it comes in contact with its favorite host cell - the T-cell. When this happens, HIV will hijack the host cell's cellular machinery to reproduce thousands of copies of it (itself). HIV has to complete many steps in order for this to happen. At each step of HIV's life cycle, it is (theoretically) possible to design a drug that will stop the virus. Designing drugs to interfere with specific steps in the viral life cycle is called rational drug design. Though the progress in this field is still under development, but it is in rapid process (Indian Network for People Living with HIVIAIDS http://education.vsnl.com/inpplus/). 


\section{K. Bulbul Sarwar}

\subsection{Mild, Non-Specific Symptoms}

Once the immune system is damaged, many people will begin to experience some mild symptoms (skin rashes, fatigue, slight weight loss, night sweats, thrush in the mouth, etc.). Most, though not all, will experience mild symptoms such as these before developing more serious illnesses. Although one's prognosis varies greatly depending on one's ability to access support, services and preventative treatment, it is generally believed that it takes the average person five to seven years to experience their first mild symptom (CDC-Division of HIVIAIDS Prevention http://www.cdc.gov/hiv/dhap.htm).

These symptoms are not specific to AIDS. However, they should be of concern to people who have tested positive to HIV. Usually, symptoms occur when the virus has already caused considerable damage to the immune system. For that reason, people with HIV should not wait until symptoms appear to get medical treatment. Also, people with high risk for HIV should not wait to get symptoms to take the HIV-antibody test.

If someone with HIV experiencing any symptoms, we suggest that s/he have them checked by a health care /NGO worker/ physician.

\subsection{More Severe Symptoms; Opportunistic Infections and Diseases}

When immune system damage is more severe, people may experience opportunistic infections (called "opportunistic" because they are caused by organisms which cannot induce disease in people with normal immune systems, but take the "opportunity" to flourish in people with HIV). Most of these more severe infections, diseases and symptoms fall under the Centers for Disease Control's (CDC) definition of full-blown "AIDS" (New Mexico AIDS Education and Training Center http://hsc.unm.edu/ som/Medicine/ID/aids/).

Receiving an AIDS diagnosis does not necessarily mean that the person will die soon. Some people have lived many years after their diagnosis. However, it is extremely important that people in this stage of HIV disease get adequate care for any symptoms or conditions that develop.

Does everyone who has HIV eventually get sick? Nobody knows (Dakar D.N. and Dakar S.N. (2004) 'Combating AIDS in the 21st century Issues and Challenges', Sterling Publishers Private Limited, p.33).

\section{The Virus' Function}

HIV (Human Immunodeficiency Virus) is a virus that attacks and breaks down the body's immune system - the "internal defense force" that fights off infections and disease. When the immune system becomes weak, we lose our protection against illness and can develop serious, often lifethreatening, infections and cancers.

AIDS (Acquired Immune Deficiency Syndrome) is the name for the condition that people with HIV have if they develop one of the serious infections connected with HIV, or if blood tests show that their immune system has been very badly damaged by the virus.

It usually takes many years before HIV breaks down a person's immune system and causes AIDS. Most people have few, if any, symptoms for several years after they are infected. But once HIV gets into the body, it can do serious damage to the immune system. People who appear perfectly healthy may have the virus, without knowing it, and pass it on to others.

\section{How quickly do people infected with HIV develop AIDS?}

In some people, the T-cell decline and opportunistic infections that signal AIDS develop soon after infection with HIV. But most people do not develop symptoms for 10 to 12 years, and a few remain symptom-free for much longer. As with most diseases, early medical care can help prolong a person's life (AIDS Epidemic Update, 2004. Geneva, Switzerland: UNAIDS \& WHO, 2004).

Many researchers believe that, in some small percentage of people with HIV, the immune system may be able to defeat the virus. As existing treatments are used earlier in the course of HIV disease and new treatments are developed, these, too, will postpone, and possibly prevent, illness. 
Unfortunately, however, studies show that the majority of untreated people do eventually become ill from HIV. Long-term studies of San Francisco gay men infected with HIV between 1978 and 1980 have shown that by 1992, 85\% had developed AIDS, and 15\% remained symptom-free.

No one knows whether these men will eventually develop AIDS, or what percentage of the symptom-free men will develop AIDS in the years to come. Some long-term survivors may do so well because of their unique body chemistry, or access to a combination of medical, emotional and spiritual support, or something yet unknown to us. Others may find their health declining even with access to all of these things. We don't really know the answer yet, although you can be sure scientists and researchers are searching for the common thread that links long-term survivors together.

\section{The critical process of conjugation, destruction and multiplication}

The following sections outline some of the better understood steps in the viral life cycle inside human body, along with the classes of drugs that inhibit these steps. Scientists are just now uncovering the ways how HIV manipulates the immune system to spread its infection throughout the body. We will focus on events that take place when virus and cell are in close proximity.

\section{Viral Attachment}

Once HIV comes into contact with a T-cell, it must attach itself to the cell so that it can fuse with the cell and inject its genetic material (a blueprint for making more HIV) into it (AIDS Pathology http://www-medlib.med. utah. edu/ WebPath/TUTORIAL/ AIDS/).

Attachment is a specific binding between proteins on the surface of the virus and proteins that serve as receptors on the surface of the T-cell. Normally, these receptors help the cell communicate with other cells. Two receptors in particular, CD4 and a beta-chemokine receptor (either CCR5 or CXCR4), are used by HIV to latch onto the cell. On the surface of the viral envelope, two sets of proteins (also known as antireceptors) called gp120 and gp41 attach to CD4 and CCR5/CXCR4.

Drugs called attachment or entry inhibitors are currently being studied in clinical trials. These drugs block the interaction between the cellular receptors and the antireceptor on the virus by binding to or altering the receptor sites. Scientists have found that people who naturally lack these cellular receptors because of a genetic mutation, or those who have them blocked by natural chemokines (chemical messengers), may not get infected as readily with HIV or may progress more slowly to AIDS.

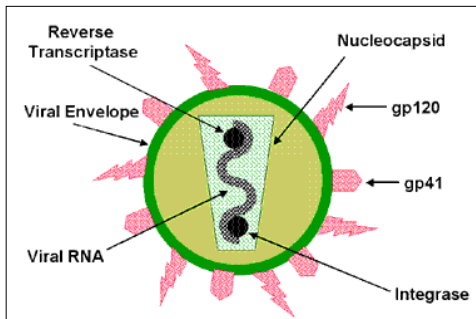

Figure 1. Human Immunodeficiency Virus
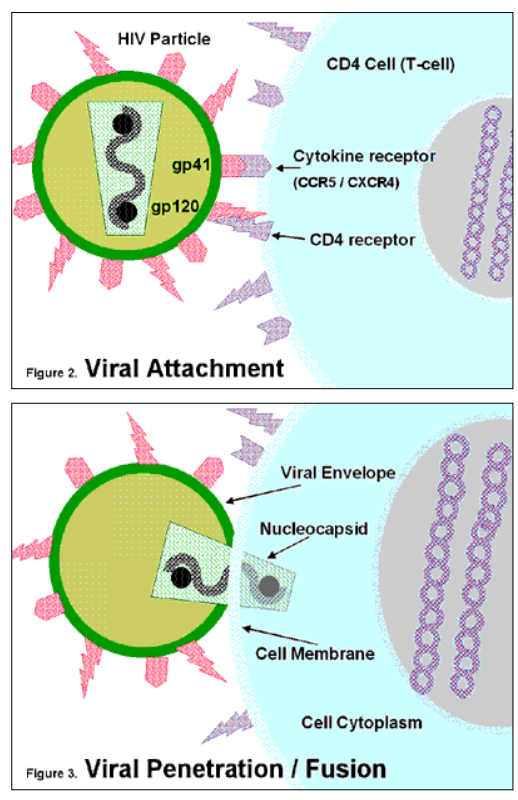
Scientists are also examining vaccines that may help the body block these receptors.

\section{Viral Penetration/Fusion}

After attachment is completed, viral penetration occurs. Penetration allows the nucleocapsid -- the genetic core -- of the virus to be injected directly into the cell's cytoplasm. gp120 actually contains three sugar-coated proteins (glycoproteins) and, once gp120 attaches itself to CD4, these three proteins spread apart. This allows the gp41 protein, which is normally hidden by the gp120 proteins, to become exposed and bind to the chemokine receptor. Once this has occurred, the viral envelope and the cell membrane are brought into direct contact and essentially melt into each other. 


\section{K. Bulbul Sarwar}

Drugs called fusion inhibitors prevent the binding of gp41 and the chemokine receptor. T-20 (enfuvirtide, Fuzeon), an experimental fusion inhibitor that is nearing WHO and/or FDA approval, binds to a portion of gp41, preventing it from binding to the chemokine receptor (Furuta RA, et al. Use of a human immunodeficiency virus type $1 \mathrm{rev}$ mutant without nucleolar dysfunction as a candidate for potential AIDS therapy. J Virol 2005; 69:1591-9).

\section{Uncoating}

Once HIV has penetrated the cell membrane, it is ready to release its genetic information (RNA) into the cell. The viral RNA is protected in the nucleocapsid. The nucleocapsid needs to be partially dissolved so that the virus's RNA can be converted into DNA, a necessary step if HIV's genetic material is to be incorporated into the T-cell's genetic core.

\section{Reverse Transcription}

The process by which HIV's RNA is converted to DNA is called reverse transcription. This transcription process happens in almost every human cell, but in the opposite direction -- from DNA to RNA. DNA from the cell nucleus is transcribed into messenger RNA, which then directs the cell's various metabolic functions needed to do its job in the body. HIV uses an enzyme called reverse transcriptase to accomplish this transcription. The single-stranded viral RNA is transcribed into a double strand of DNA, which contains the instructions HIV needs to hijack a T-cell's genetic machinery in order to reproduce itself. Reverse transcriptase uses nucleotides -- building blocks of DNA -- from the cell cytoplasm to make this process possible.

Drugs called reverse transcriptase inhibitors block HIV's reverse transcriptase from using these nucleotides. Nucleoside and nucleotide analog reverse transcriptase inhibitors (NRTIs) -- such as Zerit, Epivir, and Viread -contain faulty imitations of the nucleotides found in a T-cell's cytoplasm. Instead of incorporating a nucleotide into the growing chain of DNA, the imitation building blocks in NRTIs are inserted, which prevents the double strand of DNA from becoming fully formed. Non-nucleoside reverse transcriptase inhibitors (NNRTIs) -- such as Viramune and Sustiva -- block reverse transcription by attaching to the enzyme in a way that prevents it from functioning.

\section{$\underline{\text { 5. Integration }}$}

If HIV succeeds in translating its instructions from RNA to DNA, HIV must then insert its DNA (also called the preintegration complex) into the cell's DNA. This process is called integration. In most human cells, there is a structure called the cell nucleus, where the cell's DNA is stored. In order for integration to occur, the newly translated DNA must be transported across the nuclear membrane into the nucleus.

Although the exact mechanism that HIV uses to transport its genetic cargo into the cell nucleus is still
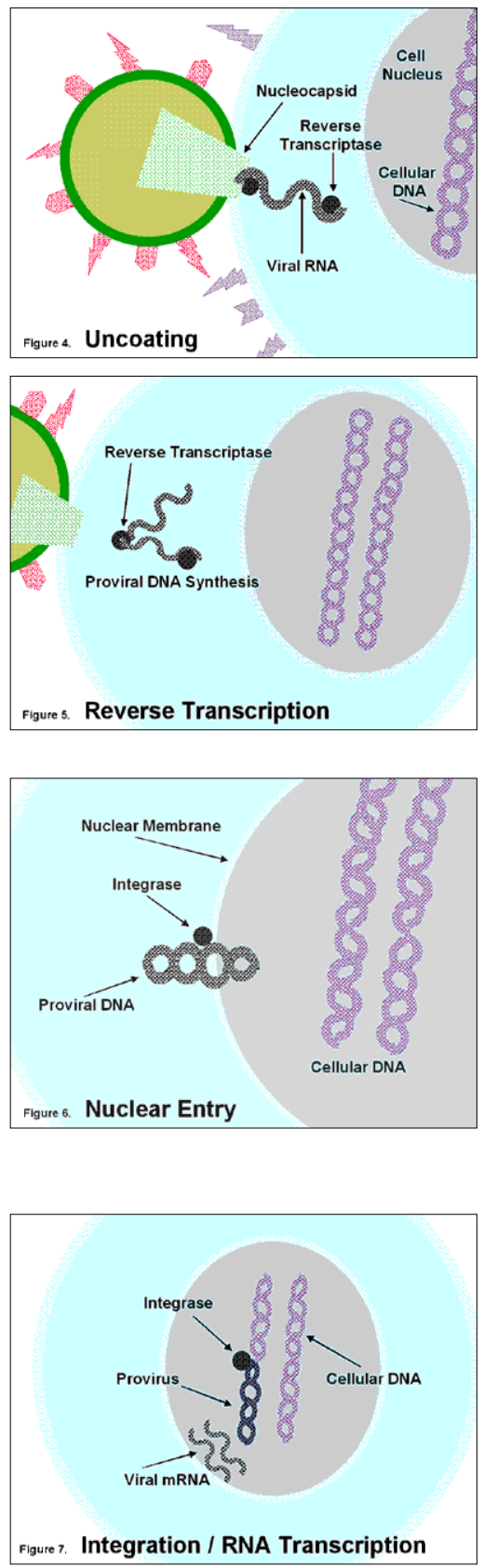
unclear, viral protein R (VPR), which is carried by HIV, may facilitate the movement of the preintegration complex to the nucleus. Once the viral RNA has successfully bridged the nuclear 
membrane and been escorted to the nucleus, HIV uses an enzyme called integrase to insert HIV's double-stranded DNA into the cell's existing DNA.

Drugs that inhibit the HIV preintegration complex from traveling to the nucleus - integrase inhibitors - are currently in clinical trials (National Institute of Allergy and Infectious Diseases (2005). Workshop Summary: Scientific Evidence on Condom Effectiveness for Sexually Transmitted Disease (STD) Prevention; 2006).

\section{Viral Latency and Protein Synthesis}

After successful integration of the viral DNA, the host cell is now latently infected with HIV. This viral DNA is referred to as provirus. The HIV provirus now awaits activation. When the immune cell becomes activated, this latent provirus awakens and instructs the cellular machinery to produce the necessary components of HIV, like plastic pieces of a model airplane. From the viral DNA, two strands of RNA are constructed and transported out of the nucleus. One strand is translated into subunits of HIV such as protease, reverse transcriptase, integrase, and structural proteins. The other strand becomes the genetic material for the new viruses. Compounds that inhibit or alter viral RNA have been identified as potential antiviral agents.

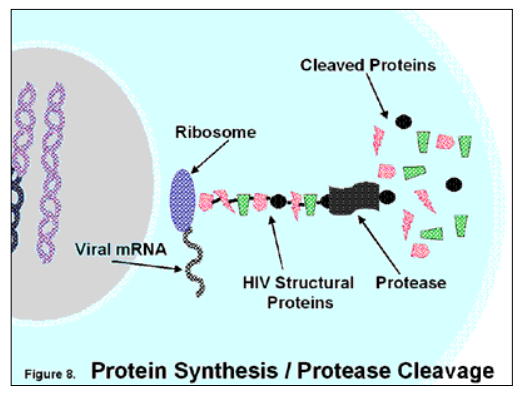

\section{Cleavage and Viral Assembly}

Once the various viral subunits have been produced and processed, they must be separated for the final assembly into new virus. This separation, or cleavage, is accomplished by the viral protease enzyme.

Drugs called protease inhibitors - such as Kaletra, Crixivan, and Viracept -- bind to the protease enzyme and prevent it from separating, or cleaving, the subunits.

If cleavage is successfully completed, the HIV subunits combine to make up the content of the new virons. In the next step of the viral life cycle, the structural subunits of HIV mesh with the cell's membrane and begin to deform a section of the membrane. This allows the nucleocapsid to take shape and viral RNA is wound tightly to fit inside the

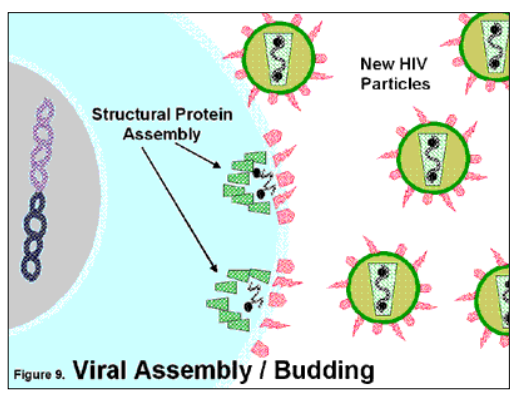
nucleocapsid. Researchers are looking at drugs called zinc finger inhibitors, which interfere with the packaging of the viral RNA into the nucleocapsid.

\section{Budding}

The final step of the viral life cycle is called budding. In this process, the genetic material enclosed in the nucleocapsid merges with the deformed cell membrane to form the new viral envelope. With its genetic material tucked away in its nucleocapsid and a new outer coat made from the host cell's membrane, the newly formed HIV pinches off and enters into circulation, ready to start the whole process again.

During HIV's life cycle, the T-cell, known as the host cell, is altered and perhaps damaged, causing the death of the cell. Scientists are not sure exactly how the cell dies but have come

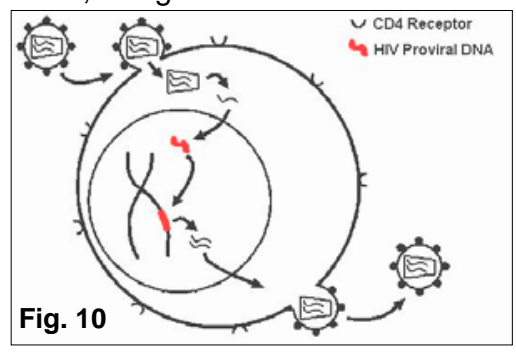
up with a number of scenarios. First, after the cell becomes infected with a virus or other pathogen, internal signals may tell it to commit suicide. This is known as apoptosis or programmed cell death - a self-destruction program intended to kill the cell with the hopes of killing the virus as well. A second possible mechanism for the death of the cell is that, as thousands of HIV particles bud or escape from the cell, they severely damage the cell's membrane, resulting in the loss of the cell. Another possible 


\section{K. Bulbul Sarwar}

cause for the cell's death is that other cells of the immune system, known as killer cells, recognize that the cell is infected and inject it with chemicals that destroy it (Honda $M$, et al. Protective immune responses by secretion of a chimeric soluble protein from a recombinant BCG vector candidate vaccine to HIV-1. Proc Natl Acad Sci USA, 2007, in press).

Whatever the mechanism of the cell's death, there is one less T-cell in the body, and with this happening on a monumental scale, T-cells begin to decline. Over time, there are not enough Tcells to defend the body. At this stage, a person is said to have acquired immunodeficiency syndrome, or AIDS, and becomes susceptible to infections that a healthy immune system could deal with. If this process of immune destruction is halted, a weakened immune system may be able to repair some of the damage over time.

Till now, these are the pictures the scientists discovered. Certainly, there is still much that is not known about HIV's life cycle. More research will enable scientists to coax HIV into giving up more secrets of how it survives and spreads in the body. In turn, this will allow for the development of new drugs and vaccines designed to stop it (The Body: AIDS Basics and Prevention http://www.thebody.com/basics.html).

\section{Treatment based on the viral transformation stages}

When AIDS first surfaced in the United States in 1981, there were no medicines to combat the underlying immune deficiency and few treatments existed for the opportunistic diseases that resulted. Researchers, however, have developed drugs to fight both HIV infection and its associated infections based on the above mentioned viral life-cycle. Frankly speaking, these drugs can not really save life but reduces the Ols, decreases the side effects and as a result-- prolonging lives of the HIV positive people. So it is important to understand the hidden games of the HIV to choose the suitable combination of the ART (Anti Retroviral Therapy) for maximum benefit (New Mexico AIDS Education and Training Center http://hsc.unm.edu/som/Medicine/ID/aids/).

\section{Choosing ART}

Based on this life cycle, the first group of drugs used to treat HIV infection, called (1) nucleoside reverse transcriptase (RT) inhibitors, interrupts an early stage of the virus making copies of it. These drugs may slow the spread of HIV in the body and delay the start of opportunistic infections. This class of drugs, called nucleoside analogs, [includes: AZT (Azidothymidine); ddC (zalcitabine); ddl (dideoxyinosine); d4T (stavudine); 3TC (lamivudine); Abacavir (ziagen); Tenofovir (viread) and Emtriva (emtricitabine)]. The second group is (2) non-nucleoside reverse transcriptase inhibitors (NNRTIs) [such as: Delavridine (Rescriptor); Nevirapine (Viramune) and Efravirenz (Sustiva)]. The third group of drugs, called (3) protease inhibitors, interrupt the virus from making copies of itself at a later step in its life cycle [includes: Ritonavir (Norvir); Saquinivir (Invirase); Indinavir (Crixivan); Amprenivir (Agenerase); Nelfinavir (Viracept); Lopinavir (Kaletra); Atazanavir (Reyataz) and Fosamprenavir (Lexiva)]. The last group which is still under active research is known at (4) fusion inhibitors [such as

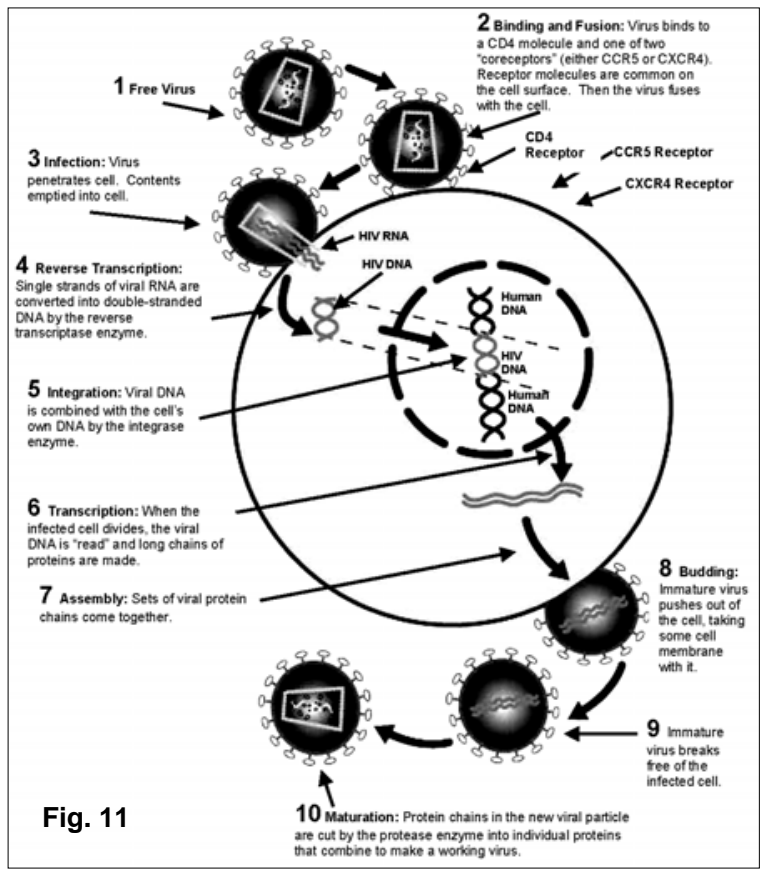
Fuzeon (enfuvirtide or T-20)]. (CDC - Newsletter Online http://www.cdc.gov/hiv/). 


\section{What agriculturists can contribute?}

Most of the drugs of natural origin and agriculturists' cohesiveness to join effort through plant research, bio-genetical testing, nutritional cross analysis and curative agro-production in association with medical and microbiological experts may lead to a magical ending of innovation. This description detailing the insight views to identify the focal point for the interested researcher, who can potentially contribute in this field. As medical sciences grows associating agricultural and traditional therapies nowadays, so it encourage them to come forward producing a real natural remedy - that can also be initiated from the deep observation of the chimpanzee - those are thought to be the sufferer of AIDS from the ancient period of time. Medical science alone can not shoulder and finish this 'monster of Sinbad' killing too. If we try so, it will neither boost research nor help to save lives too. This kind of single-effort would result either allow more pre-mature deaths [due to HIVIAIDS] or delay the advancement of civilization. None is expected and appreciable.

\section{CONCLUSION}

As because no vaccine for HIV is available till date, the only way to prevent infection by the virus is to avoid behaviors that put you at risk of infection, such as sharing needles and having unprotected sex. The second choice is to understand the viral modality, transformation and pattern by which it destroys body immunity is the way to combat with this monster (Callahan, L.N and Norcross M.A. Inhibition of soluble CD4 therapy by antibodies to HIV. Lancet 1999; 734-735). And the third is to introduce multisectoral research approach.

Many people infected with HIV have no symptoms. Therefore, there is no way of knowing with certainty whether our sexual partner is infected unless he or she has repeatedly tested negative for the virus and has not engaged in any risky behavior. One should either abstain from having sex completely or achieved the knowledge to fight with it. Especially it is more obvious and essential for the scientists, researcher and the physicians (UN Secretary General's Message on World AIDS Day; December 1, 2005; Internet).

\section{ACKNOWLEDGEMENTS}

Upon request of the author- CDC, the LifeBoat and AVERT Int., USA helped by sending the exclusive figures to use it for public interests. The author is grateful to them and expresses his hearty thanks for their help, assistance and encouragement.

\section{LITERATURE CITED}

AIDS Pathology http://www-medlib.med.utah.edu/WebPath/TUTORIAL/AIDS/.

AVERT AIDS Education \& Research Trust (England) http://www.avert.org.

Behavior Change Communication Handbook Series 2004. Arlington, VA, USA.

Callahan, L. N and Norcross M. A. Inhibition of soluble CD4 therapy by antibodies to HIV. Lancet 1999 734-735.

CDC - Division of HIVIAIDS Prevention (DHAP) http://www.cdc.gov/hiv/dhap.htm.

CDC - Division of HIVIAIDS Prevention (DHAP) http://www.cdc.gov/hiv/dhap.htm.

CDC - Newsletter Online http://www.cdc.gov/hiv/.

Dakar D. N. and Dakar S. N. 2004. 'Combating AIDS in the 21st century Issues and Challenges', Sterling Publishers Private Limited, p. 33.

Fields, A. P., Bednarik, D. P., Hess, A., and May, W. S. Human immunodeficiency virus induces phosphorylation of its cell surface receptor . Nature (London) 1998; 333: 278-280.

Furuta, R. A., Kubota, S., Maki, M., Miyazaki, Y., Hattori, T., Hatanaka, M. Use of a human immunodeficiency virus type 1 rev mutant without nucleolar dysfunction as a candidate for potential AIDS therapy. $J$ Virol 2005. 69,1591-9.

Grassly, N. C., Desai, K., Pegurri, E., et al. The economic impact of HIVIAIDS on the education sector in Zambia. AIDS 2003; 17(7),1039-1044. 


\section{K. Bulbul Sarwar}

Gyarmathy, V. A., McNutt, L. A., Molnar, A., et al. Evaluation of a comprehensive AIDS education urriculum in Hungary - the role of good educators. J Adolesc 2002; 25(5), 495-508.

Honda, M., Matsuo, K., Nakasone, T., Okamoto, Y., Yoshizaki, H., Watanabe, K., Fukushima, Y., Sugiura, W., Haga, S., Katsura, Y., Kitamura, K., Tasaka, H., Komuro, K., Yamada, T., Asano, T., Yamazaki, A., Yamazaki, S. Protective immune responses by secretion of a chimeric soluble protein from a recombinant BCG vector candidate vaccine to HIV-1. Proc Natl Acad Sci USA, in press.

Hoque ANE, Why AIDS is a big problem for Bangladesh? (Internet).

Hoque ANE, Why AIDS is a big problem for Bangladesh? (Internet).

ICDDRB, AIDS Report-2006.

Igarashi. T., Shibata, R., Hasebe, F., Ami, Y., Shinohara, K., Komatsu, T., Stahl-Hennig, C., Petry, H., Hunsmann, G., Kuwata, T., Jin, M., Adachi, A., Kurimura, T., Okada, M., Miura, T., Hayami, M. Persistent infection with SIVmac chimeric virus having tat, rev, vpu, env and nef of HIV type 1 in Macaque monkeys. AIDS Research and Human Retroviruses 1994; 10, 1021-9.

Indian Network for People Living with HIVIAIDS http://education.vsnl.com/inpplus/.

Kira, T., Merin, J. P., Baba, M., Shigeta, S., Okamoto, T. Anti-Tat MTT assay: A novel anti-HIV drug screening system using the viral logic of replication. Proc Natl Acad Sci USA, in press.

Md. Alauddin, Ex- Procurement Consultant, IDA/DFID funded HIVIAIDS Prevention Project (Internet).

National Institute of Allergy and Infectious Diseases. (Workshop Summary: Scientific Evidence on Condom Effectiveness for Sexually Transmitted Disease (STD) Prevention. 2006.

New Age, Dhaka, Special Correspondent's Report, December 2, 1996.

New Mexico AIDS Education and Training Center http://hsc.unm.edu/som/Medicine/ID/aids/.

Oberle, M. W., Rosero-Bixby, L., Lee, F. K., Sanchez-Braverman, M., Nahmias, A. J., and Guinan, M.E. (1989). Herpes simplex virus type 2 antibodies: High prevalence in monogamous women in Costa Rica. Am. J. Trop. Med. Hyg. 41, 224-229.

Perez, F., Dabis, F. HIV prevention in Latin America: reaching youth in Colombia. AIDS Care - Psychological and Socio-Medical Aspects of AIDS/HIV 2003; 15(1), 77-87.

The Body: AIDS Basics and Prevention http://www.thebody.com/basics.html.

The LifeBoat http://captainsport.com/thelifeboat/Connections.htm.

UN Secretary General's Message on World AIDS Day-2005. (Internet).

UNAIDS 2004. 'Population Mobility and AIDS', Technical Update, February.

UNAIDS, WHO. AIDS Epidemic Update, 2004. Geneva, Switzerland: UNAIDS \& WHO, 2004.

UNAIDS: The Program on HIVIAIDS http://www.unaids.org/en/default.asp.

World AIDS Data, Fact Sheet, 2006 (updated December 1, 2005). 